ORIGINAL ARTICLE

\title{
Reaching an underserved population with a randomly assigned home safety intervention
}

S G Hendrickson

Injury Prevention 2005;11:313-317. doi: 10.1136/ip.2004.007229

\begin{abstract}
Objective: To access an underserved, mobile segment of a monolingual Spanish speaking population and to improve maternal self efficacy for home safety behaviors using a culturally appropriate intervention. Design: A pre- and post-test experimental design tested differences in maternal childhood injury health beliefs (MCIHB) and controllable safety hazards (CHS). Participants were randomly assigned to experimental and control groups. Baseline data assessed demographic and study variables comparability. The intervention included counseling, assessment of maternal safety practices, and provision of safety items.

Setting: A non-urban area in Texas where low income, largely migrant Hispanics represent the majority of residents.

Participants: Eighty two mothers of 1-4 year old children.

Results: The $95 \%$ retention rate of an itinerant, hard to reach population suggests that minority participants may be receptive to culturally appropriate home visits. The intervention group demonstrated improved self efficacy for home safety behaviors $(F(2,77)=7.50, p=0.01)$. Mothers with stronger self efficacy and fewer perceived barriers had fewer accessible in-home hazards. Observed home hazard predictors were: (a) never being married; (b) poor home repair, (c) lower self efficacy for safety behaviors; and (d) control group status.

Conclusions: Safety items coupled with a home visit tailored to child age and maternal culture was an effective intervention in a hard to reach population. This study contributes to designing research for a monolingual population with limited local language proficiency and community residency. Injuries represent a major source of health disparities in these neglected populations.
\end{abstract}

Correspondence to: Dr S G Hendrickson, The University of Texas at Austin School of Nursing 1700 Red River, Austin, TX 78701, USA;

shendrickson@mail.nur. utexas.edu

Accepted 18 June 2005

M ore than one million children aged 14 years and under die from unintentional injuries annually, with $98 \%$ of deaths occurring in the developing world, the majority from traffic crashes, drowning, falls, fire, and poisoning. ${ }^{1}$ In the United States, $90 \%$ of all unintentional morbidity and $50 \%$ of all deaths caused by unintentional injury to children less than 5 years of age take place in their homes. ${ }^{2}$ Because injury deaths occur more frequently in lower income families, ${ }^{3}{ }^{4}$ and because children of poverty continue to be disproportionately represented in unintentional injury statistics, ${ }^{1256}$ it is necessary to develop interventions targeting these populations.

Appropriate subgroup interventions are almost non-existent, and home safety studies are inconsistent across several dimensions. A decade ago, a systematic review ${ }^{7}$ evaluated randomized controlled trials of home visiting programme efficacy on childhood injuries. The review indicated home visits were not significantly decreasing pediatric injury. In 2001 authors found efficacy evidence for behavior change related to education campaigns and safety equipment loan programmes, but they were unable to detect injury reduction. ${ }^{8}$ Being in the home, visualizing hazards, and the use of safety items reduced the potential to underestimate risk. ${ }^{9}$

Despite the promise of home visit interventions and safety device production, pediatric safety efficacy is inconsistently shown in the literature. ${ }^{8-12}$ King et al created a randomized trial intervention using a single home visit by a research assistant to increase use of safety measures. ${ }^{8}$ In a postintervention three year follow up phone interview, King et al determined that safety improvement did decrease injury. ${ }^{10}$ In contrast, home safety visits by a community health worker were not successful in a randomized trial intervention conducted by Gielen et al. ${ }^{11}$ Parents in both studies were given access to purchase low cost safety items. Providing free safety items to low income mothers, Sznajder et al had nurses and doctors conduct two home visits. ${ }^{12}$ The second home visit was made 6-8 weeks later. Safety improvement was significantly higher in the group given the safety items. Also providing free safety items, Watson et al found the observed changes in safety practices not large enough to affect injury rates, but parental home safety behaviors did improve. ${ }^{13}$

The current study attempted to resolve some of the inconsistencies by targeting an underserved population with a culturally appropriate intervention. There has been no specific effort to reach cultural minorities, ${ }^{3}$ who are vulnerable because they are socioeconomically, geographically, and language isolated.

In this study the Health Belief Model (HBM) and social cognitive theory (SCT) guided the research, ${ }^{14}$ exploring maternal health beliefs related to injury seriousness, susceptibility, and benefits of and barriers to home safety behaviors. Maternal self efficacy or confidence in injury prevention behaviors and observed safety hazards were also assessed before and after intervention. This seems especially critical in homes where parents have lower education levels. ${ }^{15}$

Cultural considerations (reported elsewhere) included observance of customs, community collaboration, a bilingual research team and psychometrically sound native language measures. ${ }^{16}$ These population specific design aspects were coupled with HBM and SCT guidelines to increase self efficacy for safety behaviours: ${ }^{17}$ (a) accomplishment of the desired behavior, or mastery, (b) modeling the desired action

Abbreviations: $\mathrm{CHS}$, controllable safety hazards; HBM, Health Belief Model; $\mathrm{MCIHB}$, maternal childhood injury health beliefs; SCT, social cognitive theory. 
Intervention group

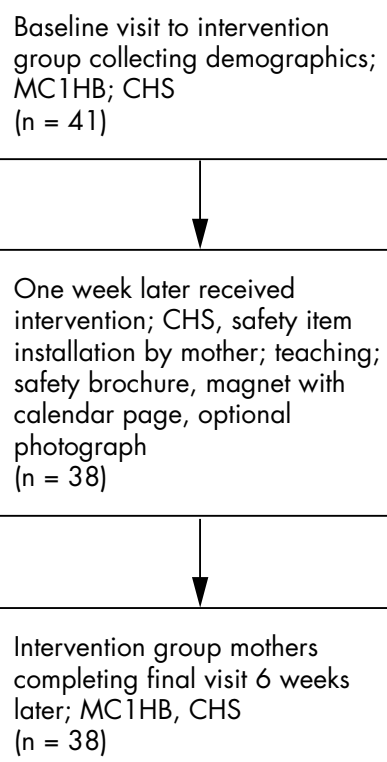

One week later received intervention; $\mathrm{CHS}$, safety item installation by mother; teaching; safety brochure, magnet with calendar page, optional photograph ( $n=38$ )

Intervention group mothers completing final visit 6 weeks later; $\mathrm{MC} 1 \mathrm{HB}, \mathrm{CHS}$ $(\mathrm{n}=38)$

\section{Attrition}

Four mothers did not complete the study due to relocations (2) employment (1), death (1)

18 month phone follow up: Telephones disconnected, no forwarding number; fax number only $(n=30)$; never answered $(n=29)$; 5 attempts per number (to be reported elsewhere)
Control group

Figure 1 Participation flow diagram. or vicarious experience, (c) persuasion, and (d) emotional arousal.

\section{METHODS}

Ethics approval was obtained through The University of Texas at Austin Human Subjects Committee. During the year before study implementation, the researcher assessed the community, including meeting leaders and target group members, to determine perception of safety items as incentives compared with stocking them at low prices in community locations. Noting cultural practices, recruiting community assistants, translating, creating, and piloting questionnaires was requisite to beginning. A pretest and post-test experimental design tested differences in maternal health beliefs and controllable safety hazards among mothers. Participants across five sites were randomly assigned to experimental and control groups in a non-urban, central Texas community.

Table 1 Demographic profile of the mothers $(n=82)$

\begin{tabular}{|c|c|c|c|c|c|c|}
\hline \multirow[b]{2}{*}{ Marital status } & \multicolumn{2}{|c|}{$\begin{array}{l}\text { Experimental } \\
(n=41)\end{array}$} & \multicolumn{2}{|c|}{ Control $(n=41)$} & \multicolumn{2}{|c|}{ Total $(n=82)$} \\
\hline & $\mathrm{n}$ & $\%$ & $\mathrm{n}$ & $\%$ & $\mathrm{n}$ & $\%$ \\
\hline Married & 24 & 58.5 & 20 & 48.4 & 44 & 53.6 \\
\hline Never married & 3 & 7.3 & 10 & 24.4 & 13 & 15.9 \\
\hline Living together & 10 & 24.4 & 6 & 14.6 & 16 & 19.5 \\
\hline $\begin{array}{l}\text { Separated/ } \\
\text { divorced } \\
\text { Housing repair needs }\end{array}$ & 4 & 9.7 & 5 & 12.2 & 9 & 11 \\
\hline In need of repair & 14 & 34.2 & 17 & 41.5 & 31 & 37.8 \\
\hline
\end{tabular}

\section{Participants}

In the target community, low income, Mexican immigrant and Mexican American mothers have language barriers, few sources of safety education, and no local emergency care. A woman was included in the study if she was the mother of a child aged 1-4 years, was English or Spanish speaking, and was agency qualified at or below $185 \%$ of the United States Federal Poverty level.

\section{Data collection}

Random assignment to the experimental or control group depended on a coin toss by the mother, putting them at ease and eliciting smiles. Mothers in the experimental group received three visits. Home visits were scheduled within a week of recruitment, then again in 1-2 weeks, then 4-6 weeks later. Mothers in the control group received two home visits, one within a week of recruitment and a second visit in six weeks. Given the mobility of the population and their lack of residency documents, establishing trust was important for retention. Data collection at visit 1 was the mother's self report using a 15 item home hazards list. Interviewing mothers first helped establish rapport before observing hazards in the intimate space of the home at visits 2 and 3. Home visit and data collection consistency was maintained using a research protocol checklist.

\section{Intervention}

The researcher counseled mothers regarding hazards reported during the first visit based on HBM constructs. One construct-behavior accomplishment-involved maternal participation in placing free safety items and correcting hazards such as putting a working battery in a smoke detector. To address modeling a desired behavior, mothers were offered the option of having a photograph taken as they 
Table 2 ANCOVA: maternal self efficacy (SE) effect size measures and power

\begin{tabular}{|c|c|c|c|c|c|c|c|c|}
\hline Source & Sum of squares & df & $\begin{array}{l}\text { Mean } \\
\text { square }\end{array}$ & $\mathbf{F}$ & p Value & $\eta^{2}$ & $\begin{array}{l}\text { Noncent } \\
\text { parameter }\end{array}$ & $\begin{array}{l}\text { Observed } \\
\text { power }\end{array}$ \\
\hline Group & 1970.06 & 1 & 1970.1 & 7.5 & 0.01 & 0.09 & 7.50 & 0.77 \\
\hline TI SE & 6748.20 & 1 & 6748.2 & 25.7 & 0.00 & 0.26 & 25.71 & 0.99 \\
\hline Total & 367625.36 & 78 & & & & & & \\
\hline
\end{tabular}

corrected a hazard. Another construct-persuasion-was targeted to individuals but built around a SafeKids brochure to stress injury prevention. To elicit susceptibility and trigger emotional arousal, mothers responded to "What do you worry about most that could happen to your child?"

\section{Objectives}

One research question hypothesized a difference in maternal health beliefs and controllable safety hazards among mothers who do or do not receive a home visit intervention after controlling for the pretest. The second research question asked "What are the predictor variables for controllable safety hazards?"

\section{Outcome measures}

Outcome measures included MCIHB scores and observed CHS scores. To enhance the quality of measurements, outcome criteria were piloted and validated before implementation in this study. Measurement questionnaires reliability met (one subscale) and exceeded Cronbach alphas of 0.70 .

\section{Sample size}

A power analysis for a $2 \times 2$ ANCOVA $(\alpha=0.05$, power $=0.87$, $r=0.36$ ) determined a sample size of 40 mothers for each group (intervention and control). A power analysis for a regression equation with an $r$ of 0.28 , an $\alpha$ of 0.05 , and power of 0.89 required a sample of 80 mothers.

\section{STATISTICAL METHODS}

Data analysis consisted of: descriptive data, ranges, means, and standard deviations for the major variables and bivariate relations between personal and study variables. A one way ANOVA followed by Tukey's Honestly Significant Difference (HSD) test assessed differences in the major variables among the five recruitment sites. ANCOVA addressed differences between experimental and control groups for MCIHB and CHS. Hierarchical regression determined CHS predictability. Paired samples $t$ tests were used to compare MCIHB and CHS measures at the first and last visits because data in the two measures were correlated.

\section{RESULTS}

\section{Participant flow}

Attrition is described in the participant flow diagram (fig 1). A comparison of the major variables at $\mathrm{Tl}$ revealed no significant difference between the two groups.

\section{Recruitment}

The five recruitment sites represented local assistance resources. Participants chose the first visit date within the same or following week of recruitment. At recruitment we explained that at the first visit mothers would schedule follow up visits 2-6 weeks later depending on intervention or control group status. This community was sampled due to geographic disadvantages including: (a) distance from a hospital, (b) possible rural delays in reporting injuries, and (c) limited access to trained providers, equipment, or communication systems. ${ }^{18}$ Recruitment occurred from 1998 to 1999 , and the participant retention rate was $95 \%$.

\section{Baseline data}

Eighty two women participated. Of these, $87 \%$ were Hispanic, most of Mexican descent. The remaining 13\% were white. Twenty three percent of mothers reported moving 3-5 times over the past four years. The average education did not differ significantly between groups. In the experimental group $(\mathrm{n}=41)$, the mean (standard deviation) education was 8.95 (SD 3.63) years (range $0-17)$; in the control group $(n=41)$, the mean was 9.20 (SD 3.17) years (range 1-16). Almost half the mothers were isolated by not driving or being near public transportation. Women agreeing to be in this study were safety conscious with $93 \%$ reporting seatbelt use.

Table 1 presents further demographic information for mothers in each group. Marital status and housing repair needs became home hazard predictor variables.

Eighty two percent of the mothers had one child between the ages of 10 and 47 months, $11 \%$ had two children, 5\% had three children, and $2 \%$ had four children in the target age group. There was no statistical significance between groups.

\section{Numbers analyzed}

ANOVA followed by Tukey's HSD test determined no significant difference among the five sites on the major variables. ANOVA indicated more observable hazards in households where mothers were never married. Paired samples $t$ tests compared MCIHB and CHS scores at Tl $(\mathrm{n}=82)$ and T2 $(\mathrm{n}=78)$ for the experimental and control groups. While the control group had no significant change in scores, the experimental group had a significant improvement from $\mathrm{T} 1$ to $\mathrm{T} 2(\mathrm{n}=37)$ on recognition of injury consequences and self efficacy scales. The CHS score decreased significantly in the experimental group.

\section{Outcomes and estimation}

Analysis of covariance (table 2) indicates a significant difference in self efficacy between groups $(\mathrm{F}(2,77)=7.50$, $\mathrm{p}=0.01)$. There was no significant difference by group for the other four MCIHB subscales.

Table 3 Hierarchical regression analysis for personal, $\mathrm{MClHB}$ and group variables predicting visit $2 \mathrm{CHS}$ ( $n=78)$

\begin{tabular}{|c|c|c|c|c|}
\hline Variable & B & SE B & $\beta$ & p Value \\
\hline \multicolumn{5}{|l|}{ Step 1} \\
\hline Never married & 1.87 & 0.66 & 0.21 & 0.006 \\
\hline Housing repair & -1.17 & 0.42 & -0.20 & 0.007 \\
\hline \multicolumn{5}{|l|}{ Step 2} \\
\hline Self efficacy & -0.03 & 0.01 & -0.20 & 0.006 \\
\hline \multicolumn{5}{|l|}{ Step 3} \\
\hline $\begin{array}{l}\text { Group }(0=\text { Control; } \\
1=\text { Experimental) }\end{array}$ & -3.52 & 4.60 & -0.57 & 0.000 \\
\hline \multicolumn{5}{|c|}{$\begin{array}{l}\text { Beta weights and values shown are from the full model at Step } 3 \text {. } \\
\text { Step 1: } r^{2}=0.25 ; F(2,75)=12.61, p \leqslant 0.01 \\
\text { Step 2: } r^{2}=0.37 ; r^{2 \Delta}=0.12 ; F^{\Delta}(2,73)=6.61, p \leqslant 0.01 \\
\text { Step 3: } r^{2}=0.65 ; r^{2 \Delta}=0.29 ; F^{\Delta}(1,72)=58.72, p \leqslant 0.01\end{array}$} \\
\hline
\end{tabular}


Table 4 Visit 1 MCIHB and CHS Pearson correlation coefficient $(n=82)$

\begin{tabular}{lccccc}
\hline MCIHB \& CHS & Consequences & Possibilities & Benefits & Barriers & Self efficacy \\
\hline Consequences & 1.00 & 1.00 & & & \\
Possibilities & $0.30^{*}$ & 0.10 & 1.00 & & \\
Benefits & 0.21 & -0.07 & $0.32^{*}$ & 1.00 & \\
Barriers & $0.34^{*}$ & 0.04 & -0.08 & 0.17 & 1.00 \\
Self efficacy & -0.04 & 0.02 & 0.01 & -0.10 & $-0.35^{*}$ \\
CHS & 0.02 & & & \\
\hline \multirow{2}{*}{$p \leqslant 0.05$ (all two tailed). } & & & & \\
\hline
\end{tabular}

A statistically significant difference was found in CHS between groups $\mathrm{F}(1,77)=99.6, \mathrm{p}=0.00$. Mothers receiving the intervention indicated improved self efficacy for home safety behaviors not only by scoring higher on that subscale, but also by having fewer observed hazards. All significant ANCOVA findings occurred after the intervention.

Results of the hierarchical regression analyzing the effects of the predictor variables on controllable safety hazards are shown in table 3 . The selection of variables was based on significant bivariate correlations of the variables with CHS.

\section{Ancillary analyses}

Table 4 presents a correlation matrix across the sample for the MCIHB and CHS variables.

\section{DISCUSSION}

\section{Interpretation}

The experimental group had a significant increase in self efficacy scores and decrease in the CHS score. Hazards were predicted by: mothers never being married, more housing repair needs, lower self efficacy, and being in the control group. Intervention success is largely attributed to preintervention preparation.

There are various study limitations. MCIHB scores reflect the mothers' self report, and as such are subject to social desirability. The CHS observation was not blinded to group by having an outside evaluator because of family outsider distrust. Safety items were provided, though cost analysis is not available in this report. Given the mobility of the population no longitudinal study followed to assess actual injury rate.

Publications regarding randomized safety interventions to support populations who do not speak the language of their host country were not found in the literature.

\section{Generalizability}

Results are not generalizable to other populations, age groups, or injury sources. In an attempted follow up 18 months later, both by mail and by telephone, only 20 mothers could be reached as a result of relocation with no forwarding address and disconnected phone service. Most participants rented housing. US Census data indicate about one third of people living in renter occupied housing in 1993 had moved in the previous year. The study follow up rate might be different with "average Americans" who make 11.7 moves in an entire lifetime. ${ }^{19}$ Reporting study results informs and increases systematic review content.

\section{Overall evidence}

Maternal self efficacy for safety behaviors increased and hazards decreased when participants received an intervention visit. Mothers discussed differences in national attitudes and beliefs, ranging from leaving children home alone to negligence and culpability from poisonings. One mother stated "here in the United States they will put you in jail" for leaving children unsupervised. Housing repair needs were intrinsically linked to poverty. Control families did not purchase safety items over the course of the visits.

Nurses and other health advocates are designing home visit programmes to build cultural understanding. ${ }^{2021}$ However, because researchers are ethically responsible for investigating why any segment of the population suffers disproportionately, pre-intervention assessment is essential. Target population feedback can determine if families are resistive to purchasing low cost safety items, compared with the gifting of safety items as participation incentives. Researchers not providing safety items (for example, smoke detectors) to families already endangered by economic hardship must recognize that no matter how robust the intervention, mothers will likely chose food and shelter expenditures, which they see as actual needs, over potential risk prevention needs. Furthermore, target populations may migrate from countries where child safety devices are unaffordable, generally unavailable, and as a result undervalued..$^{22}$ Through home visits, these often isolated mothers experienced a positive connection to the community, recognition, and the cultural respect of a study conducted in their native language.

Interventions to reduce hazards in the home need culturally appropriate, interdisciplinary, randomized trials measuring injury outcomes. ${ }^{23}$ As noted in a Cochrane review of home modification to reduce injury, designing rigorous studies, expanding collaboration, and population focused implementation may improve the research and the acceptability to participants. ${ }^{24}$ Delivery of interventions whether by a research assistant, community health worker, or nurse needs further evaluation and may be community specific.

\section{Key points}

- The home setting accounts for about $33 \%$ of all injuries; however, insufficient evidence exists for the effectiveness of safety items and even less evidence exists of culturally appropriate trials within mobile, minority groups.

- Living conditions, childhood safety beliefs, and practices of an underserved sample were examined. Cultural elements facilitated interaction, supported participant retention, and focused on community inequalities.

- Home hazard predictors were: (a) never being married; (b) poor home repair, (c) lower self efficacy for safety behaviors.

- Increasing a mother's self efficacy for safety behaviors, together with modification of the home environment, decreased access to hazards.

- Creating an intervention in the language of the target population begins to allow cultural contextual injury differences to be investigated. 
Home visits to single mothers, and those needing home repairs, working in conjunction with local agencies, may be one way to prioritize efforts. This study is critical to clinicians triaging client needs and home visits, to researchers trying to inform the knowledge base specific to national subgroups, and to policy makers influential in injury data surveillance.

\section{ACKNOWLEDGEMENTS}

The author would like to thank Shirley C Laffrey, PhD, RN, Heather A Becker, PhD, LPC, Patricia C Avant, PhD, RN, Melanie S Percy, PhD, RN, and Elizabeth Reifsnider, PhD, RN; Ruth Wells and the Women, Infants \& Children Program; community assistants Misia Ovalle and Rufina Perez; Dawn Surratt RN, MSN; Home Depot and Mr Mo Mogadassi; Bobby MacPherson, RN, MSN.

A Motorola Small Grant funded the study. No actual or potential conflict of interest exists between the author and Motorola Corporation.

\section{REFERENCES}

1 SafeKids Worldwide. Childhood unintentional injury worldwide: meeting the challenge [October, 2002]. Available at http://www.safekids.org/ (accessed 20 August 2004).

2 Durlak JA. Successful prevention programs for children and adolescents. New York: Plenum Press, 1997:115-30.

3 Health Development Agency. Evidence and Guidance Collaborating Centre for the Prevention of Accidental Injuries. Available at http://www.hda.nhs.uk/ documents/injuries_in_children_inequalities.pdf (accessed 1 June 2005).

4 Christoffel T, Gallagher SS. Injury prevention and public health: practical knowledge, skills, and strategies. Gaithersburg: Aspen Publishers, 1999:91.

5 DiGuiseppi C, Roberts I. Individual-level injury prevention strategies in the clinical setting. The Future of Children 2000;10:53-82.

6 Children's Safety Network. Available at http:// www.childrenssafetynetwork.org/ (accessed 28 August 2004).

7 Roberts I, Kramer MS, Suissa S. Does home visiting prevent childhood injury? A systematic review of randomized controlled trials. BMJ 1996;312:29-33.

8 King WJ, Klassen TP, LeBlanc J, et al. The effectiveness of a home visit to prevent childhood injury. Pediatrics 2001;108:382-8.
9 Chen LH, Gielen AC, MCDonald EM. Validity of self-reported home safety practices. Inj Prev 2003;9:73-5.

10 King WJ, LeBlanc J, Barrowman NJ, et al. Long term effects of a home visit to prevent childhood injury: three year follow up of a randomized trial. Inj Prev 2005;11:106-9.

11 Gielen AC, McDonald EM, Wilson ME, et al. Effects of improved access to safety counseling, products, and home visits on parents' safety practices: results of a randomized trial. Arch Pediatr Adolesc Med 2002;156:33-40.

12 Sznajder M, Janvrin MP, Albonico V, et al. Evaluation of the effectiveness of an injury prevention kit delivery for toddlers in four French cities. Arch Pediatr 2003;10:510-16.

13 Watson $M$, Kendrick D, Coupland C, et al. Providing child safety equipment to prevent injuries: randomised controlled trial. BMJ 2005;330:178.

14 Bandura A. Perceived self-efficacy in the exercise of personal agency. Psychol Bull Br Psychol Soc 1989; 10:411-24.

15 Girasek DC, Gielen AC. The effectiveness of injury prevention strategies: what does the public believe? Health Educ Behav 2003;30:287-304.

16 Hendrickson SG. Beyond translation...cultural fit. West J Nurs Res 2003;25:593-608

17 Strecher V, McEvoy De Vellis B, Becker M, et al. The role of self-efficacy in achieving health behavior change. Health Educ Q 1986;13:73-91.

18 Office of Technology Assessment. Rural emergency services - Special report. Washington DC: US Government Printing Office, 1989.

19 U. S. Census Bureau. Highlights national population trends. Available at http://www.census.gov/population/www/pop-profile/highlgt.html (accessed 5 April 2005)

20 Norr KF, Crittenden KS, Lehrer EL, et al. Maternal and infant outcomes at one year for a nurse-health advocate home visiting program serving African Americans and Mexican Americans. Public Health Nurs 2003;20:190-203.

21 Olds D, Korfmacher J. The evolution of a program of research on prenatal and early childhood home visitation: special issues introduction. J Comm Psychol 1997:25:1-7.

22 Hendrie D, Miller TR, Orlando $M$, et al. Child and family safety device affordability by country income level: an 18 country comparison. Inj Prev 2004; 10:338-43.

23 Rivara FP. Prevention of injuries to children and adolescents. Inj Prev 2002;8(suppl 4):iv5-iv8.

24 Lyons RA, Sander LV, Weightman AL, et al. Modification of the home environment for the reduction of injuries. Cochrane Database Syst Rev 2004;2. 